Revista Eletrônica de Educação do Curso de Pedagogia

do Campus Avançado de Jataí da Universidade Federal de Goiás

[Vol I - n.1 ] [jan/jul] [ 2005 ]

ISSN: $1807-9342$

\title{
EM BUSCA DE UMA IDENTIDADE: O CURSO DE PEDAGOGIA DA UFG
}

\author{
NETO, Alípio Rodrigues de Sousa - Mestre em Educação/UFG -Docente CAJ/UFG \\ alípio.neto@brturbo.com.br
}

RESUMO: Tendo como referencial as reflexões de GOODSON, bem como as discussões realizadas por SILVA, MOREIRA, OLIVEIRA e SANTOS sobre a História do Currículo, este texto tem como objetivo apresentar algumas conclusões a que chegamos, a partir do estudo realizado no Mestrado em Educação da Universidade Federal de Minas Gerais, sobre o processo de reformulação curricular ocorrido na Faculdade de Educação da Universidade Federal de Goiás no período que se estende do final da década de 70 ao início dos anos 80. Entendido como um recorte dentro do conhecimento social mais amplo, o currículo é produto de um contexto histórico/social no qual se manifestam interesses diversos. Desta forma, procuramos evidenciar as discussões referentes à reformulação do curso de Pedagogia, bem como os conflitos entre posições que expressavam interesses diversos, tanto no plano nacional como local, as condições internas à Faculdade de Educação da Universidade Federal de Goiás que propiciaram a vitória de um dado projeto de formação do profissional pedagogo, as resistências de segmentos ligados diretamente ao curso de Pedagogia (especialistas, professores e alunos da Instituição) que, afetados em seus interesses pela nova proposta curricular implantada em 1984, se posicionaram contrários à reformulação.

Palavras chaves: História do Currículo - Pedagogia - Formação de Professores

\begin{abstract}
Having as reference the reflections of Goodson, as well as the discussions done by Silva, Moreira, Oliveira and Santos about the History of the Curriculum, the current dissertation has as its object of investigation, the process of curriculum reformulation which occurred in the Education Faculty at the Federal University of Goiás during the period that goes from the end of the $70^{\text {'s }}$ decade until the beginning of the $80^{\text {'s }}$. Understood as a small cut out of the larger social knowledge, curriculum is a product of a historical/social context in which several interests are displayed. This way, we try to show, in the present study, the discussions referring to the reformulation of the Pedagogy course as well as the conflicts among positions that express many interests, in the national as well as local (Goiás) plans, the internal conditions of the Education Faculty at the Federal University of Goiás that caused the victory of a certain project of formation of the Pedagogue professional, the resistances of segments directly connected to the Pedagogy course (specialists, teachers and students of the institution), which, affected in their interests for the new curriculum proposal implanted in 1984, have positioned themselves against the reformulation.
\end{abstract}

Key-words: History of curriculum - Pedagogy- Formation of the teachers

Introdução

Em decorrência das transformações ocorridas na sociedade brasileira, da expansão do sistema educacional e das reflexões sobre a formação do educador, que se deram em nível nacional, no final dos anos 70 e no início da década de 1980, implantou-se na Faculdade de Educação da Universidade Federal de Goiás uma nova proposta curricular para o curso de Pedagogia, em 1984. Esta proposta assumiu a formação do educador como um projeto de caráter marcadamente político (compromisso com as classes populares) e a docência como a base da identidade profissional do pedagogo. Assim, o curso reformulado 
teria como objetivo formar o professor das séries iniciais do ensino fundamental e das disciplinas pedagógicas da Habilitação Magistério do segundo grau.

O novo currículo foi um dos primeiros no país a se voltar exclusivamente para a formação do profissional da educação tendo na docência sua base teórico/prática. Ao suspender as habilitações em Orientação Educacional, Supervisão e Administração Escolar de primeiro e segundo graus, o novo projeto buscava alternativas face ao modelo tecnicista de formação do pedagogo, implantado no início da década de 70 . No entanto, essa reformulação curricular não foi consensual, encontrando a oposição de parte dos professores e dos alunos da FE/UFG, dos Sindicatos de Orientadores e Supervisores. Embora não consensual, implantou-se o novo currículo, concretizando discussões que apontavam a necessidade de se formar um novo educador.

A par do exposto, o presente trabalho tem como preocupação central o estudo do processo de construção e de implantação do currículo do curso de Pedagogia da FE/UFG, processo este que se desenrolou no final dos anos 70 e início dos anos 80. Procuramos, através desta investigação, compreender a natureza do processo de construção desta proposta curricular. Isso porque a avaliação de um currículo ativo (efetivamente desenvolvimento na sala de aula) não pode desconsiderar a fase em que se discutiu, se elaborou e se implantou um novo projeto curricular. A fase de construção de um currículo pré-ativo (aqui entendido como currículo escrito ou currículo como documento) pode evidenciar uma série de questões (visões divergentes, busca de consolidação de posições no âmbito acadêmico, resistências à implantação de um novo projeto curricular) as quais podem se manifestar no momento de implementação do projeto curricular.

Segundo Goodson (1995), o currículo é uma construção complexa que envolve uma variedade de áreas e níveis, tornando importante, ao se considerar esta variedade, a distinção entre currículo escrito e currículo como atividade em sala de aula.

Apesar desta distinção, existe uma estreita relação entre os dois processos de realização do currículo. Por isso mesmo, ao considerar apenas o currículo escrito, corre-se o risco de afirmar que ele “... é irrelevante para a prática, ou seja, que a dicotomia entre o adotado [currículo pré-ativo] e o currículo ativo, tal como é vivenciado e posto em prática, é completa e inevitável” (Goodson, 1995, p. 107). 
Para este autor, tal dicotomia explica-se pelo fato de que o entendimento da construção do currículo em sua fase pré-ativa não tem merecido a devida atenção, o que compromete estudos mais completos e que estabeleçam a relação entre a fase de construção do currículo e a fase prática. Mas o autor adverte: "Isto, naturalmente, não visa sugerir um vínculo direto ou facilmente discernível entre a fase pré-ativa e a fase interativa. Também não significa que, ocasionalmente, a fase interativa não possa subverter ou transcender a fase pré-ativa"(Goodson, 1995, p. 109).

No entanto, ao se discutir o processo de construção de uma proposta curricular pode-se buscar evidenciar a formulação de "parâmetros fundamentais" para a sua realização em fase posterior (fase interativa). Esses parâmetros são historicamente situados e construídos por intermédio do confronto entre posições divergentes que, por sua vez, são condicionados pelo contexto histórico mais amplo. Tais conflitos não cessam com a simples implantação de uma grade curricular, mas podem sobreviver, metamorfoseando-se ao longo do tempo e prolongando de uma forma diferente o conflito da fase de elaboração. Ou seja, não se trata, em um processo avaliativo, de se estabelecer uma comparação entre o currículo escrito e o currículo ativo, que pode ser inócua, como adverte Goodson. Mas trata-se de estudar o currículo como um processo permanente de construção/reconstrução, em que se manifestam posições, interesses, visões diferenciadas e mesmo divergentes.

Assim, ao privilegiarmos o estudo do processo de construção e implantação do currículo de 1984, procuramos contribuir para o processo de avaliação que vem ocorrendo no interior da FE/UFG, o qual, provavelmente, desembocará em uma nova proposta curricular para o curso de Pedagogia.

\section{História do currículo: delimitando o problema}

Segundo Moreira (1994) e Silva, T. (1996), o interesse pelo estudo do currículo centrado em um enfoque histórico emerge das formulações da Nova Sociologia da Educação ${ }^{3}$, corrente do pensamento educacional, originado na Inglaterra, para a qual “... os currículos são construções sociais e correspondem a uma seleção da cultura, subordinada a interesses ...” (Moreira, 1994, p. 273). Entendido como um recorte dentro do conhecimento social mais amplo, o currículo acaba por privilegiar certos conhecimentos que, desta forma, 
assumem a condição de conhecimentos legítimos, a serem transmitidos às futuras gerações. Ou, como afirma Silva, T.: “O currículo não é constituído de conhecimentos válidos, mas de conhecimentos considerados socialmente válidos" (Silva, T., 1996, p. 79; grifo do autor).

Assim, é o jogo entre as forças sociais que acaba por definir o que deve ou não ser ensinado e aprendido no espaço escolar. Por isso mesmo, o currículo é uma construção histórica e social envolvida em relações de poder. Como dizem Santos e Oliveira:

O currículo é expressão de forças e de interesses conflitantes na sociedade, e a história do currículo busca compreender o que torna possível a inclusão e a exclusão de certas formas de conhecimento nos diferentes cursos oferecidos pelas instituições educacionais. (Santos e Oliveira, 1998, p. 15)

Por ser uma construção histórica e social, a produção do currículo não é um processo lógico, coerente, articulado por posturas acadêmicas (científicas) imparciais que estabeleceriam o que deve ou não ser ensinado às novas gerações. Como enfatiza Silva, T.:

O processo de fabricação do currículo não é um processo lógico, mas um processo social, no qual, convivem, lado a lado com fatores lógicos, epistemológicos, intelectuais, determinantes sociais menos "nobres" e menos "formais" tais como interesses, rituais, conflitos simbólicos e culturais, necessidades de legitimação e de controle, propósitos de dominação dirigidos por fatores ligados à classe, à raça, ao gênero. (Silva, T., 1996, p. 79)

Isso significa dizer que reduzir a história do currículo a um processo lógico, linear, é perder de vista fatores diversos que interferem no processo de sua construção.

No mesmo sentido, ao tratar da complexidade da história do currículo, Moreira (1994) afirma que a compreensão da história do currículo de um curso requer que sejam considerados diferentes contextos (internacionais, societário, institucional e biográfíco). Para o mesmo autor, devem ainda fazer parte das preocupações do campo da história do currículo:

(a) história das idéias e teorias formuladas pelos especialistas; (b) história de reformas e propostas curriculares 
elaboradas nos diversos sistemas de educação; (c) estudos de caso que examinem as relações entre intenções e práticas; (d) história das disciplinas curriculares; (e) história do currículo de um curso. (Moreira, 1994, p. 274)

Discutimos neste trabalho o contexto societário, entendido como o contexto sócio-político-econômico brasileiro, que propiciou condições para a emersão e a "legitimação" de determinados discursos, posturas, tendências no plano educacional, ao mesmo tempo que tornou "ilegítimos" outros discursos, posturas, tendências. Trabalhamos, ainda, com o contexto institucional, o qual, para efeito de realização deste estudo, diz respeito a encontros, seminários, congressos e mesmo produções acadêmicas de âmbito nacional, regional e local. Nesse sentido, procuramos acompanhar o processo de discussão sobre a formação do educador ocorrido tanto em contextos nacionais, como regionais e locais, buscando estabelecer uma relação entre os três níveis do que aqui chamamos de contexto institucional.

A distinção entre currículo escrito e currículo ativo, proposta por Goodson (1995) é um referencial importante para a realização de nossa investigação. Se o currículo escrito expressa um ideário social, político e educacional de uma época, ele próprio, por sua vez, é fruto de um processo histórico que delimita e restringe as opções, possibilitando a vitória ou a derrota de posturas, visões. Assim, o currículo escrito estabelece certas diretrizes e parâmetros para a sua realização na fase ativa.

Pelo fato de ser ele uma construção histórico/social ao mesmo tempo que expressão de um processo conflituoso, a análise do currículo escrito perde todo seu sentido se ocorrer de forma isolada do contexto que o produziu. Como afirma Goodson:

... os conflitos em torno da definição do currículo escrito proporcionam uma prova visível, pública e autêntica da luta constante que envolve as aspirações e objetivos de escolarização. É somente por esta razão que importa aumentar a nossa compreensão sobre esse conflito curricular. (Goodson, 1995, p. 17)

Da mesma forma, a da compreensão do currículo em sua fase ativa só será possível se entendermos o processo de sua construção. Mas, como nos adverte Goodson (1995), isso não quer dizer que se possa estabelecer, de forma fácil, a relação entre as duas 
fases do currículo, já que a fase de realização pode transcender ou subverter a fase préativa. Como consequência disto, a "transgressão" dos parâmetros concretizados no currículo escrito tem as suas raízes em fase anterior à sua elaboração. Até mesmo a "transgressão" é limitada pelos parâmetros estabelecidos na fase pré-ativa, momento em que se estabelecem normas e critérios de avaliação da prática ou do currículo em sua fase ativa. Assim, se não analisarmos o processo de elaboração do currículo, corremos o risco de aceitá-lo como um pressuposto e, como conseqüência, de buscarmos variáveis dentro da sala de aula. Ou, como afirma Goodson (1995, p. 24): "Estaríamos aceitando como 'tradicionais' e 'pressupostos', versões de currículo que num exame mais aprofundado podem ser consideradas o clímax de um longo e contínuo conflito" (Goodson, 1995: 24).

Com o objetivo de encontrar respostas para este problema, levantamos dois questionamentos principais:

a) Quais as tendências presentes na discussão sobre o profissional formado pelo curso de Pedagogia, sobre a divisão do trabalho escolar, sobre os especialistas, tanto em nível local, isto é, da FE/UFG, como em nível nacional, no final dos anos 70 e início dos anos 80 ?

b) Quais as condições internas e externas à FE/UFG que propiciaram a vitória de uma dada proposta curricular?

Com o intuito de buscar respostas às questões apresentadas acima, utilizamos como fonte principal de consultas alguns documentos escritos (atas de reuniões de Departamentos da FE, artigos publicados na revista Inter-Ação da Faculdade de Educação, nos Cadernos CEDES, na Revista Educação e Sociedade, nos Cadernos da ANDE, relatórios finais e Anais de congressos, encontros e seminários). De forma complementar, servimo-nos ainda de depoimentos de docentes, alunos, profissionais da rede pública de ensino que vivenciaram o processo de construção e implantação da proposta curricular.

\section{Algumas Conclusões}

O processo de formulação e de implantação do currículo do curso de Pedagogia da FE/UFG se desenrolou em um contexto de crise sócio/política/econômica, de organização da sociedade civil, de ampliação dos debates em torno dos problemas sociais 
de um modo geral, e sobre a educação, de forma mais específica. Foi um momento de recusa do autoritarismo e de luta pela democratização da sociedade.

Considerando esse contexto, procuramos entender as discussões entre os educadores brasileiros sobre a divisão do trabalho no espaço escolar e sobre a necessidade de buscar alternativas para a formação de um novo profissional da educação, capaz de responder às necessidades dos setores populares.

Essas questões fazem parte das preocupações dos educadores críticos do final dos anos 70 e início da década de 1980. No entanto, apesar de existir um certo consenso entre os educadores sobre a necessidade de formar um profissional da educação de novo tipo, comprometido com os interesses da escola pública e dos setores populares, o mesmo não se pode dizer a respeito da visão dos educadores sobre a divisão do trabalho na escola e sobre o profissional que o curso de Pedagogia deveria formar.

Para alguns, a complexificação do sistema educacional exigia uma divisão das tarefas educacionais entre os profissionais das escolas. No entanto, esta divisão do trabalho, teria gerado uma fragmentação do trabalho escolar e uma hierarquização de funções, criando condições para a proliferação de relações de poder autoritárias no interior do espaço escolar, produzindo, como resultado, a subordinação do trabalho docente às autoridades tecnoburocráticas. Ao mesmo tempo que se questionava a organização do trabalho na escola, criticava-se, também, a formação do profissional pedagogo. O curso de Pedagogia deveria, então, ser reformulado, uma vez que estaria formando profissionais acríticos, sem compreensão da realidade educacional brasileira, desconhecedores da dimensão política de suas atividades e descomprometidos com os interesses dos segmentos populares. Propunha-se, assim, formar o educador com uma visão ampla e profunda da escola, comprometido com a luta por uma sociedade mais justa e com uma educação voltada para os interesses da maioria da população.

As críticas direcionadas à divisão do trabalho escolar, à atuação dos especialistas e ao próprio curso de Pedagogia não significavam, para todos os educadores, negar as especializações ou a formação de especialistas. As críticas, segundo essa posição, apontavam para a necessidade de se rever tanto a formação como a atuação deste profissional. 
A segunda posição, a exemplo da anterior, também criticava a atuação e a formação do especialista e o curso de Pedagogia que formava profissionais acríticos. No entanto, percebia a divisão do trabalho de forma negativa, por esta submeter o trabalho docente a uma hierarquia e a uma burocracia responsáveis pela expropriação de seu saber. Desta perspectiva, a divisão das tarefas no espaço escolar dividia as atividades de planejamento e de execução, o trabalho intelectual do trabalho manual. Essa divisão do trabalho obedecia a determinados interesses que beneficiavam uma elite, em detrimento da maioria, havendo necessidade de formar um profissional da educação capaz de romper com a fragmentação do trabalho escolar. Segundo essa posição, a permanência da formação do especialista, mesmo com a reformulação do currículo do curso de Pedagogia, não garantiria a superação da divisão do trabalho escolar. Neste caso, não se deveria formar especialistas em supervisão, administração, orientação, inspeção, mas um educador que, com uma formação teórico-prática consistente e com uma visão profunda da realidade educacional pudesse atuar em diversas atividades no espaço escolar. Foi a posição defendida pela FE/UFG.

Cabe frisar que a proposta curricular implantada em 1984 na FE, não desconsiderava a complexidade do fenômeno educacional. O conceito de educador presente no currículo pré-ativo não era sinônimo de professor, embora considerasse que todo professor seria um educador, nem reduzia a atividade pedagógica ao exercício da docência ou, em outras palavras, não reduzia a educação à escolarização (Coêlho, 1985). No entanto, expressa uma opção política em formar profissionais/professores construída ao longo de vários anos, à medida que os docentes da FE iam conhecendo a realidade do ensino público em Goiás, através da realização de pesquisas e da participação em encontros e seminários. Segundo a Exposição de Motivos que fundamenta a proposta curricular implantada em 1984, a formação de professores seria a principal tarefa a ser assumida pela educação em Goiás.

Esta não foi uma posição consensual entre os docentes da instituição, havendo, inclusive, a apresentação de propostas, nas quais a formação de especialistas seria mantida. No entanto, a maioria dos docentes da FE assumiram a posição, que acabou por se tornar vitoriosa, de suspender a formação do especialista, fosse na graduação, fosse na pósgraduação. 
Os professores assumiam posturas diferenciadas diante da nova proposta curricular, agrupando-se, basicamente, em três grupos. Um primeiro grupo tinha uma posição claramente contrária ao novo currículo, mantendo-se afinado com a proposta de formação de especialistas para a educação. Embora tivesse assumido uma posição favorável à reformulação, um segundo grupo de professores não renovou sua atuação profissional, ou seja, manteve uma dicotomia entre o que era proposto pelo currículo pré-ativo e a sua prática na sala de aula. Um terceiro grupo assumiu efetivamente a proposta, buscando articular coerentemente a proposta do novo currículo com sua prática profissional.

Vê-se deste modo, que sobreviveram posturas, visões sobre educação e sobre a formação de profissionais no curso Pedagogia, bem como a permanência de práticas profissionais de parte do corpo docente da FE que interferiram no processo de implementação do currículo o que, talvez, tenha comprometido o desenvolvimento do projeto curricular implantado em 1984. No entanto, um exame mais consistente dessa questão depende de uma investigação que, relacionando o processo de discussão, construção e implantação da proposta curricular da FE com o processo de sua implementação, possibilite averiguar até que ponto houve coerência entre o currículo préativo e o currículo ativo ou, em outras palavras, entre a teoria e a prática.

Com relação à posição assumida pelos alunos diante da proposta curricular, pode-se afirmar que, antes da implantação do novo currículo, o corpo discente manteve-se dividido em dois grupos. Um grupo majoritário de alunos conservava-se, de certa forma, "indiferente" à reformulação curricular, por já ter garantido o direito de concluir o curso na habilitação que estava cursando. Assim, a reformulação não os atingia diretamente. Havia um segundo grupo constituído por aproximadamente 35 alunos, que optou por concluir o curso na nova grade curricular.

Posteriormente à reformulação curricular, a "indiferença" dos estudantes transformou-se em resistência ativa à proposta de formação de docentes para a primeira fase do ensino fundamental e para o curso de Magistério, implantada na FE. A resistência se deveu pelo fato de que as habilitações, sobretudo em orientação e supervisão educacional, ofereciam maior status ao profissional da educação, além de uma melhor remuneração. Havia ainda uma questão relacionada ao mercado de trabalho. Para muitos o projeto curricular, implantado em 1984, limitava a possibilidade de atuação do profissional 
pedagogo. Os novos alunos, que ingressaram na FE após a implantação do novo currículo, passaram, então, a questionar a proposta do curso de Pedagogia por entenderem que ele se voltava exclusivamente para a formação de docentes. No entanto, a resistência não deve ser atribuída somente ao fato de que os alunos que ingressaram no curso de Pedagogia, a partir de 1984, não conheciam a nova proposta curricular, sua história, seu processo de construção e implantação. Se assim fosse, a grande maioria do corpo discente que estava presente na FE no momento em que se discutia a reformulação curricular teria assumido o projeto de formação do novo profissional pedagogo, fato que não ocorreu. Desta forma, questões ligadas a mercado de trabalho e a status e remuneração, foram mais decisivas para fomentar a resistência de parte do corpo discente do que a participação ou não no processo de construção da nova proposta curricular, o que afetou a implementação do currículo préativo da FE.

Os profissionais de primeiro e segundo graus também se dividiram com relação à proposta de suspensão da formação dos especialistas. Nos Encontros das Escolas Públicas de Goiânia ocorridos em 1982 e 1983, as discussões referentes à formação do educador mais especificamente do profissional a ser formado pelo curso de Pedagogia - foram adiadas, pois poderia provocar a divisão dos profissionais da rede pública de ensino. $\mathrm{O}$ movimento destes profissionais buscava uma articulação em torno de reivindicações comuns tais como melhoria salarial, plano de carreira e condições de trabalho.

Mas, durante o Encontro Estadual de Goiás para a Reformulação dos Cursos de Preparação de Recursos Humanos para a Educação ${ }^{4}$ (outubro de 1983), evento preparatório do I Encontro Nacional, realizado em Belo Horizonte, em novembro de 1983, a divisão da categoria foi inevitável. Ainda que não consensuais, as conclusões a que chegaram os participantes deste Encontro foram no sentido de que o curso de Pedagogia deveria voltarse para a formação de docentes das matérias pedagógicas do curso de Magistério e das matérias da primeira fase do ensino fundamental e que a formação de profissionais em administração, supervisão, orientação e inspeção fosse suspensa, direcionando os esforços para formar bem o novo professor.

As posições retiradas no evento no que se refere à reformulação do curso de Pedagogia já vinham sendo discutidas desde 1979 no interior da FE/UFG. Pode-se dizer, então, que parte dos profissionais de $1^{\circ}$ e $2^{\circ}$ graus assumiram o projeto que, posteriormente 
se concretizou na reformulação de 1984 o que provocou uma cisão entre os profissionais da educação. Se por um lado, os professores normalistas viam no novo currículo a possibilidade de continuação de sua formação, de outro, os especialistas percebiam o novo currículo como uma ameaça à categoria.

No entanto, a oposição à nova proposta curricular por parte dos especialistas, não se transformou em uma resistência consistente uma vez que ocorreram transformações significativas, tanto no movimento dos profissionais da educação como no próprio sistema educacional do Estado de Goiás, a partir de meados da década de 80.

Em relação ao movimento dos profissionais de primeiro e segundo graus da rede pública de ensino, ocorreu a fusão entre Sindicatos de Orientadores (Associação dos Orientadores do Estado de Goiás), de Supervisores (Associação dos Supervisores do Estado de Goiás) e dos Professores (Centro de Professores de Goiás), formando-se, desde então, um Sindicato único: o SINTEGO. Este fato é importante na medida em que os especialistas tiveram o seu poder de articulação limitado pela própria necessidade de se estabelecer princípios, reivindicações comuns entre os profissionais da educação. Não havia, a partir do momento de fusão dos Sindicatos, a possibilidade de formulação de uma proposta específica de orientadores ou supervisores. As propostas deveriam ser formuladas pelo coletivo que estava dividido com relação à reformulação do curso de Pedagogia. Assim, se por um lado, a fusão entre os Sindicatos fortaleceu a categoria (todos são profissionais da educação) na luta por melhores salários, melhores condições de trabalho, plano de carreira, por outro, enfraqueceu os especialistas ao dificultar, ou mesmo impossibilitar, a mobilização desses segmentos em torno de questões específicas, como a relacionada à reformulação do currículo do curso de Pedagogia da FE, que os atingia diretamente.

Mas, um fator primordial que minou o poder dos especialistas foi a implantação do cargo de coordenador pedagógico no sistema educacional do Estado, em substituição à figura do especialista. Nesse sentido, a atuação de docentes da FE que apoiavam o projeto curricular implantado em 1984 na estrutura burocrática da Secretaria Estadual de Educação, fortaleceu a docência em detrimento das atividades tecnoburocráticas.

A partir de 1982, quando o ex-governador Íris Rezende assumiu o governo do Estado, muitos de seus acessores foram recrutados junto à Universidade, sendo que vários professores da FE passaram a ocupar cargos na Secretaria de Educação. Como 
conseqüência, criou-se a figura do coordenador pedagógico, deslocando os orientadores e supervisores para a sala de aula, restringindo, desta forma, o espaço de atuação do especialista. Deste modo, a proposta curricular, que previa a formação de docentes no curso de Pedagogia, se fortaleceu, o que não significa dizer que a proposta foi aceita. O que ocorreu foi a vitória de um projeto, que acabou por se consolidar, em detrimento de outros.

Assim, o projeto curricular de 1984 não pode ser percebido apenas nos limites da academia. Sua Repercussão se fez sentir em todo o Estado de Goiás com conseqüências importantes não somente na reordenação do sistema educacional, priorizando a docência, mas interferindo na organização da própria categoria dos profissionais de primeiro e segundo graus.

Todavia, a constatação de que o novo currículo conseguiu consolidar-se não nos permite afirmar que o projeto de formação de profissionais docentes, expresso no currículo pré-ativo tenha sido cumprido, uma vez que ocorreu resistência de professores e alunos, o que não pode ser desconsiderado no momento de avaliar o currículo ativo da Instituição. Os conflitos em torno da proposta curricular, que emergiram no processo de sua construção, se prolongaram na fase de implementação da proposta. Mas até que ponto essas resistências teriam comprometido a proposta inicial é algo que, talvez, não se possa mensurar. Assim sendo, torna-se importante abrir uma nova investigação que, ao articular as diversas fases de realização do currículo (processo de construção, implantação e implementação), possa oferecer uma resposta à questão.

De qualquer forma, a proposta curricular implantada pela FE/UFG teve grande repercussão no plano nacional, não porque tenha privilegiado a docência na formação do educador (princípio formulado ao longo de vários anos no interior do movimento dos educadores), mas pelo fato de que foi a primeira proposta a suspender, tanto na graduação como na pós-graduação, a formação do especialista. Por esse motivo, vários docentes da FE foram convidados para discutir a proposta em diversas instituições e em encontros de educadores. Essa repercussão nacional, contudo, não nos permite afirmar, como faz Silva, A. (1998), que a proposta implantada em 1984 na FE influenciou no processo de elaboração de outros projetos curriculares. Isto porque desconhecemos, pelo menos até o momento, como se deu o processo de discussão e de elaboração do currículo em outras instituições. Embora admitindo a existência de uma discussão nacional sobre a formação do educador e, 
mais especificamente, sobre o curso de Pedagogia, em cada caso é a dinâmica interna de cada Instituição que vai estabelecer, a partir dos embates entre grupos com visões e posturas diferentes, os limites ou os parâmetros com os quais se edificará uma proposta curricular. Tal questão nos remete à discussão sobre quais as condições que propiciaram a vitória, no interior da FE, de um dado projeto curricular para o curso de Pedagogia. Subdividimos essa discussão nos seguintes itens: a) condições políticas e sociais, em nível nacional e local (Goiás); b) condições internas da UFG; e c) condições internas da FE.

No final dos anos 70 e início da década de 1980, o Brasil passava por um processo de transição política alimentado por uma profunda crise econômica, abrindo espaços para a organização da sociedade civil. Nesse contexto, os educadores brasileiros se organizaram, passando a questionar tanto o regime como a política educacional vigente.

Os debates travados no interior do movimento propiciaram o amadurecimento de propostas que culminaram no I Encontro Nacional sobre Reformulação dos Cursos de Preparação de Recursos Humanos para a Educação, realizado em Belo Horizonte (1983), com o estabelecimento de alguns princípios que deveriam ser aprofundados, pelo debate, nas diversas Instituições Educacionais do país. Foi um período, portanto, em que se repensava coletivamente a formação do educador e, mais especificamente, a formação do profissional pedagogo. No processo de mobilização e de discussão, surgiram diversas propostas que apontavam para a reformulação dos cursos de Pedagogia.

O Comitê Pró-Formação do Educador, fundado em 1980, teve como objetivo principal mobilizar e fomentar a discussão dos educadores brasileiros em torno da questão. Por isso mesmo, esta entidade nunca chegou a apresentar uma proposta de reformulação dos cursos de licenciatura e de Pedagogia. Mesmo porque, as diversidades locais e regionais não permitiram a elaboração de uma proposta única que contemplasse todas as necessidades e interesses presentes em cada Instituição formadora de educadores.

Em Goiás, a exemplo do que ocorria no restante do país no início dos anos 80, ocorriam transformações no plano político e social. A oposição chegou ao governo estadual, ao mesmo tempo em que de intensificava a mobilização dos profissionais da educação. Os Encontros das Escolas Públicas de Goiânia foram importantes momento não apenas para denunciar o caos em que se encontrava a educação no Estado, mas também 
porque criou condições para que os profissionais da educação pudessem se articular em torno de reivindicações comuns.

Os Encontros das Escola Públicas propiciaram uma aproximação da FE/UFG da realidade educacional do sistema público de ensino, resultando daí um maior compromisso dessa Instituição com a escola pública, com a luta pela valorização do professor e uma atuação mais próxima ao então Centro de Professores de Goiás (CPG).

Foi nesse contexto nacional e regional que ocorreram, no interior da UFG, os debates sobre os cursos de licenciaturas e de Pedagogia. Em 1980, aconteceu o I Seminário sobre Licenciatura na UFG, no qual se estabeleceram princípios que deveriam nortear as futuras reformulações dos cursos formadores de profissionais para a educação, dentre os quais destacamos o comprometimento da Universidade com as necessidades locais, a formação de qualidade do educador, garantindo-lhe mercado e boas condições de trabalho, a rejeição da licenciatura curta e da formação do especialista, e a articulação entre os diversos segmentos da Universidade com o objetivo de romper com a formação fragmentada do educador.

Posteriormente, em 1982, foi designada uma Comissão pela Pró-Reitoria de Graduação (PROGRAD), com o objetivo de avaliar o regime de crédito, então em vigor na UFG. O parecer da Comissão mostrou a necessidade de se implantar o sistema seriado semestral já que, segundo avaliação realizada, o sistema de créditos causava prejuízos para a vida acadêmica. No mesmo ano, várias outras Comissões foram organizadas pela PROGRAD com o objetivo de apresentar propostas para a melhoria dos cursos de licenciaturas na UFG. Todo esse processo culminou com a realização, em abril de 1983, do Simpósio de Graduação da UFG, no qual se definiram critérios e princípios orientadores da reformulação dos currículos dos cursos de licenciatura e de Pedagogia. Este momento representou um salto qualitativo na forma de perceber o currículo. Tratava-se, a partir de então, não de modificações superficiais na grade curricular, através do corte de uma ou outra disciplina e do acréscimo de outras, aumentando ou diminuindo carga horária, mas sim de uma reformulação curricular orientada pela necessidade de integrar ensino, pesquisa e extensão, definindo claramente o profissional a ser formado pelo curso, o núcleo epistemológico definidor das disciplinas que comporiam o novo currículo e a relevância das mesmas na formação do profissional da educação. 
Chegamos, assim, à terceira condição referente ao movimento interno da Instituição, o qual propiciou não somente a elaboração de uma nova proposta curricular, mas a vitória de uma dada visão a respeito do profissional que o curso de Pedagogia deveria formar.

Desde 1979, quando da consulta feita pelo $\mathrm{MEC}^{5}$ sobre as discussões então realizadas na FE sobre a reformulação do curso de Pedagogia, esta Instituição apresentava como proposta a suspensão da formação dos especialistas. No entanto, esta não era uma posição consensual entre os docentes da FE. No Seminário Pró-Formação do Educador evidenciou-se, de forma mais clara, a divergência entre os docentes da Instituição. Em primeiro lugar, porque a participação dos pedagogos, entendidos como especialistas, aparece como uma concessão feita pela Comissão organizadora do evento, a qual estava composta, basicamente, por docentes dos Departamentos de Fundamentos (DF) e de Administração Escolar (DAE) ${ }^{6}$. Nesses Departamentos concentrava-se uma maioria de docentes que defendiam a suspensão da formação dos especialistas. No Departamento de Práticas Educacionais (DPE), composto principalmente de pedagogos, manifestava-se com maior peso a posição contrária à proposta de suspensão da formação do especialista. Entretanto, a posição que propunha que o curso de Pedagogia tivesse como objetivo a formação de docentes encontrava apoio entre a maioria do corpo docente da FE/UFG.

Em segundo lugar, o Seminário evidenciou pelo menos três posições entre o corpo docente da Instituição, referentes à reformulação do currículo do curso de Pedagogia. Uma defendia a formação do técnico, percebendo na reformulação do curso uma pseudosolução para a formação do pedagogo. Outra defendia a necessidade de se formar um profissional de novo tipo, voltado para a docência, com uma visão ampla do fenômeno educativo e capaz de assumir as funções necessárias ao bom desempenho das atividades pedagógicas. Por fim, havia uma terceira posição que se caracterizava pela dúvida em relação aos rumos que a reformulação curricular deveria tomar.

Ainda, com relação às condições internas à $\mathrm{FE}$ que propiciaram a vitória de um dado projeto curricular, é importante se destacar que as discussões referentes ao curso de Pedagogia foram fomentadas: 
a) Pelo processo de qualificação dos professores da FE que, no período em discussão, ingressaram em cursos de mestrado e doutorado, entrando em contato com a produção de outros centros acadêmicos relacionados à formação do educador;

b) Pela produção de pesquisas dos docentes que elegeram, como foco central de suas investigações, a escola pública;

c) Pela organização do Comitê Pró-Formação do Educador em Goiás cuja sede nacional, até 1982, estava na FE/UFG. Por intermédio do Comitê, os docentes da Instituição estavam em contato permanente com outras Universidades, já que participaram ou mesmo sediaram diversos eventos de caráter nacional nos quais, então, se divulgavam propostas formuladas em outros centros acadêmicos;

d) Pela dinâmica de discussões empreendida pelo Presidente ${ }^{7}$ do Colegiado de Cursos de Ciências Pedagógicas ${ }^{8}$, que permitiu uma melhor compreensão dos problemas enfrentados por professores e alunos mantendo, desta forma, uma discussão permanente sobre o curso de Pedagogia.

Estas eram, portanto, as condições internas da FE/UFG que, aliadas às condições externas propiciaram a reformulação do currículo do curso de Pedagogia. A hegemonia do grupo vencedor no interior da Instituição foi definitiva para a elaboração e implantação do novo projeto curricular. Todo o contexto externo influenciou, de forma significativa, o processo de discussão. No entanto, foi o embate entre os grupos presentes na FE que acabou por definir a proposta vencedora e a proposta derrotada. Mas uma vitória ou uma derrota que não é definitiva já que, na fase de implementação da proposta curricular, os conflitos presentes no processo de elaboração do currículo pré-ativo se prolongaram.

Por fim, gostaríamos de pontuar outras questões que nos parecem relevantes e que merecem maiores atenções ou mesmo novas investigações.

Já dissemos que é importante aprofundar a compreensão do currículo ativo com o intuito de perceber até que ponto foi possível cumprir o que foi estabelecido no currículo pré-ativo de 1984. Outro tema de relevo seria tentar investigar até que ponto o novo currículo influenciou a atuação do profissional pedagogo e se contribuiu para a formação de um profissional com uma visão ampla do processo educativo e para o rompimento da fragmentação do trabalho escolar. Esta proposta de trabalho requer uma investigação da 
prática deste profissional formado na proposta curricular implantada em 1984. Por fim, após 1984, foram abertos cursos de extensão nos municípios de Jataí e Catalão. Nesses locais, as pessoas que compunham o quadro docente não haviam participado do processo de elaboração do novo currículo. Desta forma, como os conflitos vivenciados no interior da FE não foram transpostos para esses locais, seria importante verificar se este fato contribuiu para que houvesse uma relação mais próxima entre currículo pré-ativo (teoria) e currículo ativo (prática).

Finalizando, esperamos que esta investigação tenha avançado na compreensão da fase de construção/implantação do currículo pré-ativo da FE. De fato, nosso interesse era buscar oferecer maiores subsídios ao processo de avaliação da proposta de 1984, de modo a contribuir para que se possa compreender um pouco mais um dado período da Educação em Goiás, bem como sugerir a realização de novas investigações.

1 O II Encontro das Escolas Públicas de Goiânia foi realizada em 1983 subdividido em duas etapas. A primeira ocorreu entre os meses de maio e junho, quando, então, foram organizados microencontros em mais de 70 escolas do município de Goiânia. Já a segunda etapa ocorreu nos dias 23 , 24 e 25 de junho, produzindo-se, como resultado deste evento, um documento-síntese onde os profissionais da educação do município de Goiânia apresentavam suas posições sobre diversos pontos referentes aos principais problemas que afetavam o sistema educacional. A discussão sobre a necessidade de formação de um novo profissional pedagogo não canalizava as atenções dos educadores que se viam envolvidos em discussões mais emergenciais tais como: estatuto do magistério; condições de trabalho; remuneração etc...

2 A partir de meados da década de 70, com a divulgação das Indicações de Chagas, desencadeia-se no país um processo de discussão sobre o curso de Pedagogia. No entanto, gradativamente, a discussão sobre a formação de educadores se amplia, atingindo outras licenciaturas. Nesse processo de discussão o I Seminário de Educação Brasileira e a I e II Conferências Brasileira de Educação, ocorridas respectivamente em 1980 e 1982, representaram momentos importantes, pois, propiciaram a divulgação de produções acadêmicas, trocas de experiência e a própria organização dos educadores em nível nacional. Foi no interior da I CBE que nasceu o Comitê Pró-Formação do Educador, que exerceu importante papel na ampliação das discussões sobre a formação do educador. O primeiro Presidente desta entidade foi o Professor Ildeu Moreira Coêlho da FE/UFG.

3 Segundo Forquim (1995), a Nova Sociologia da Educação surgiu como decorrência de uma vigorosa produção acadêmica nas áreas de Ciências Sociais e Educação na Inglaterra em 1970. No entanto, ao contrário do que se possa imaginar, não se constituiu como um movimento homogêneo. Diz o autor: "Parece-nos que é mais pela recusa de uma certa tradição dominante no âmbito da sociologia britânica da educação (caracterizada por uma abordagem através de grandes inquéritos sociais centrados no acesso à educação e nos efeitos sociais da educação) do que na colocação em prática de uma nova perspectiva positiva e coerente que a NSE [Nova Sociologia da Educação] encontrou sua identidade e unidade aparente. Nessa perspectiva, a referência aos trabalhos interacionistas americanos, à fenomenologia social e às contribuições possíveis da sociologia do 
conhecimento, tinha sobretudo uma função polêmica e pragmática: visava mostrar que era possível uma sociologia diferente ou antes que, em Sociologia da Educação, eram possíveis outras abordagens" (Forquim, 1995, p. 162; grifos do autor).

4 Entre os dias 21 e 25 de novembro de 1983, ocorreu o I Encontro Nacional sobre Reformulação dos Cursos de Preparação de Recursos Humanos para a Educação, promovido pelo MEC/Sesu, em Belo Horizonte. Como preparação para este encontro organizou-se na FE/UFG, nos dis 17, 18 e 19 de outubro de 1983, também soba coordenação do MEC/Sesu, o Encontro Estadual de Goiás para Reformulação dos Cursos de Preparação de Recursos Humanos para a Educação. Esse evento foi de grande importância, uma vez que definiu princípios que norteariam as reformulações curriculares das Instituições de Educação Superior de Goiás, voltadas para a formação do educador e que seriam discutidasem âmbito nacional no Encontro de Belo Horizonte.

5 Em 1979, a Secretaria de Ensino Superior do MEC consultou três Universidades sobre os estudos desenvolvidos nessas instituições para a reformulação do curso de Pedagogia e das habilitações. Dentre essas Universidades estava a Faculdade de Educação da Universidade Federal de Goiás (UFG) que, em documento elaborado em junho de 1979, em resposta à solicitação do MEC, assumiu uma postura contrária às habilitações. Outra posição assumida pela Faculdade de Educação da UFG foi a de que deveria se envolver todas as instituições de ensino superior no processo de discussão sobre os cursos de Licenciatura e de Pedagogia. A consulta deveria envolver não somente três, mas todas as Faculdades de Educação.

6 A estrutura departamental da Faculdade de Educação passou por sucessivas modificações no transcorrer da década de 70 e início da década de 80 . O quadro abaixo apresenta a estrutura departamental entre 1970 e 1982.

\begin{tabular}{|l|l|l|}
\hline 1970/Departamentos & $1972-1976 /$ Departamentos & 1977-1982/Departamentos \\
\hline Didática & Didática & Práticas Educacionais \\
\hline Disciplinas Pedagógicas & Administração Escolar & Administração escolar \\
\hline & Fundamentos da Educação & Fundamentos da Educação \\
\hline & $\begin{array}{l}\text { Psicologia Educacional e } \\
\text { Biologia Educacional }\end{array}$ & \\
\hline
\end{tabular}

Fonte: Arquivos da FE/UFG (Citado por Rezende, 1977:142).

Em meados de 1982, houve uma discussão no Conselho Departamental que redefiniu a organização dos Departamentos a partir de 1983. Foram criados quatro Departamentos: Departamento de Fundamentos e Métodos da Educação (DFME); Departamento de Administração e Ciências (DAC); Departamento de Comunicação e Práticas da Educação (DCPE); Departamento de Biologia e Psicologia Aplicados à Educação (DBPAE). Em 23 de outubro de 1985, esses quatro Departamentos foram extintos, organizando-se três novos Departamentos: Departamento de Pedagogia (DePe); Departamento de Fundamentos e Práticas de Ensino (DFPE); Departamento de Estudos Aplicados à Educação (DEAE).

7 Ildeu Moreira Coêlho, primeiro Presidente do Colegiado de Cursos de Ciências Pedagógicas, despontou, no período em discussão, como uma lideranças intelectual no interior da Universidade Federal de Goiás e da Faculdade de Educação onde exercia suas atividades docentes. $\mathrm{O}$ reconhecimento do seu papel como intelectual, articulado a um contexto de mobilização e organização de docentes e estudantes, característica marcante do final dos anos 70 e início dos anos 80, tanto em Goiás como no Brasil, criou condições para que Coêlho se tornasse um referencial importante nas discussões sobre a educação no Estado. Posteriormente, essa liderança ultrapassa os limites do Estado quando, em 1980, assumiu a coordenação nacional do Comitê Pró-Formação do Educador por indicação de docentes de Goiás presentes na I CBE. 
8 Um marco importante no processo de reformulação do curso de Pedagogia foi a eleição do professor Ildeu Moreira Coêlho para Presidente do Colegiado de Curso de Ciências Pedagógicas. A Presidência do Colegiado de Curso era um cargo chave na estrutura administrativa da Faculdade de Educação e da própria UFG. Por meio deste Colegiado definiam-se os objetivos do curso e a orientação do ensino. Ainda, o Presidente do Colegiado era representante da FE no Conselho Coordenador de Ensino e Pesquisa (CCEP) da Universidade. (Coêlho, 1985)

\section{Referências Bibliográficas}

ALVES, Maria Helena Moreira. Estado e oposição no Brasil (1964-1984). Petrópolis, Vozes,1985. ANDE. Anais da I Conferência Brasileira de Educação. São Paulo, Ed. Cortez, 1980.

BRASIL. Ministério da Educação e Cultura. Universidade Federal de Goiás. Pró-Reitoria de Extensão. Relatório do I Seminário sobre licenciatura da UFG. Goiânia, 1980a. (Mimeogr.)

1980. Goiânia, 1980b.

Faculdade de Educação. Conselho Departamental. Atas de 1977 a

Universidade de Brasília. Relatório Preliminar do I Seminário Regional sobre

Reformulação dos Cursos de Preparação de Recursos Humanos para a Educação. Brasília, 1981a (Mimeogr.).

Universidade Federal de Goiás. Faculdade de Educação. Sobre a redefinição do educador. Goiânia, 1981b (Mimeogr.).

Secretaria de Ensino Superior. Reformulação dos cursos de preparação de

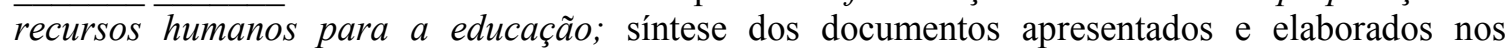
Seminários Regionais/1981. Rio de Janeiro, MEC/SESu, 1982a. (Mimeogr.).

.Universidade Federal de Goiás. Pró-Reitoria de Graduação. Relatório da Comissão designa da pela Portaria n. 00425 (Avolta do Regime Seriado). Goiânia, 1982c.

Goiânia, $\overline{1982 d . ~(M i m e o g r .) . ~}$

Faculdade de Educação. I Encontro das escolas Públicas de Goiânia.

.Secretaria de Ensino Superior. Documento final do Encontro Nacional do

Projeto de Reformulação dos Cursos de Preparação de Recursos Humanos para a Educação. Belo Horizonte, 1983a. (Mimeogr.).

.Universidade Federal de Goiás. Pró-Reitoria de Graduação. Simpósio de abril: princípios e critérios de reforma curricular da UFG. Boletim Prograd, n. 2, 1983 b.

.Faculdade de Educação. Relatório da primeira fase do II Encontro de

Escolas Públicas de Goiânia. Goiânia, 1983c (Mimeogr.).

$\overline{\text { Goiânia. }}$ Goiânia, $\overline{1983 \mathrm{~d} \text { (Mimeogr.). }}$.

Documento sintese do II Encontro de Escolas Públicas de

.Quanto a formação do técnico. 1983e (Mimeogr.)

. Colegiado de Cursos de Ciências Pedagógicas. Resolução n. 207/84.

Currículo do curso de Pedagogia da UFG; Exposição de Motivos. . Goiânia, 1984. (Mimeogr.).

$1986^{\mathrm{a}}$ (Mimeogr.).

.Faculdade de Educação. Relatório de Atividades (1982-1986). Goiânia,

da Universidade Federal de Goiás. Goiânia, 1986b (Mimeogr.).

Avaliação da reformulação curricular do curso de Pedagogia

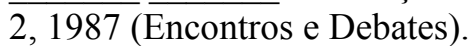

Formação do Educador: a busca da identidade do curso de Pedagogia. INEP, n.

BRZEZINSKI, Iria. Pedagogia, pedagogos e formação de professores: busca e movimento.

Campinas, São Paulo: Papirus, 1996 (Coleção Magistério: Formação e Trabalho Pedagógico)

Dilemas institucionais e curriculares do curso de Pedagogia: do professor primário ao

professor "primário". In: ENCONTRO NACIONAL DE DIDÁTICA E PRÁTICA DE ENSINO, 7, 1994. Goiânia. Anais: conferências, mesas redondas e simpósios, Goiânia, v. 2, 1994. p. 324-364. 
Pedagogia e Formação de Professores: Dilemas e perspectivas. In: ENCONTRO NACIONAL DE DIDÁTICA E PRÁTICA DE ENSINO, 8, 1996. Florianópolis. Anais: conferência, simpósios, mesas redondas. Florianópolis, v. 2, 1996. p. 525-542.

CADERNO ANDE (Associação Nacional de Educação), São Paulo, n. 1, 1981.

CADERNOS CEDES, São Paulo, n. 6, p.14-27, 1982.

CANDAU, Vera Maria F. Novos rumos da licenciatura. Rio de Janeiro. INEP/ Pontifícia Universidade Católica do Rio de Janeiro, 1987.

CAFÉ, Maria Helena Barcellos. A reformulação do curso de pedagogia. Inter-Ação, Revista da Faculdade de Educação da UFG. Goiânia, v. 5, n. 8, p. 11-18, 1981.

CANESIN, Maria Tereza. Um protagonista em busca de interlocução: um resgate da História do movimento de professores da rede pública de $1^{\underline{o}}$ e $2^{\underline{o}}$ graus em Goiás, na conjuntura 1979/1989. São Paulo:PUC, 1993. (Tese de Doutorado) - Pontifícia Universidade Católica de São Paulo CHAGAS, Valnir. Formação do magistério: novo sistema. São Paulo: Atlas, 1976.

COÊLHO, Ildeu Moreira. A formação do educador em questão. Inter-Ação, Revista da Faculdade de Educação da UFG. Goiânia, v. 6, n.1/2, p. 1-7, jan./dez., 1982a.

$\mathrm{O}$ educador e a construção de uma Nova Escola. Inter-Ação, Revista da Faculdade de Educação da UFG. Goiânia, v. 6, n. 1/2, p. 183-188, jan./dez., 1982 b.

. Realidade e utopia da universidade: memorial. Goiânia, Ed. da UFG, 1996.

CONFERÊNCIA BRASILEIRA DE EDUCAÇÃO (I CBE), 1, 1980, São Paulo. Anais.Florianópolis: Cortez, 1981.

CONFERÊNCIA BRASILEIRA DE EDUCAÇÃO (II CBE), 2, 1982, Anais. Belo Horizonte: Diniz, 1982.

DOMINGUES, José Luiz, PÁDUA, Maria Terezinha de Souza e MELO, Orlinda Maria de Fátima C.. Licenciatura em Pedagogia: uma possibilidade. Inter-Ação, Revista da Faculdade de Educação da UFG. Goiânia, v. 7, n. 1-2, p. 69-79, jan./dez., 1983.

EDUCAÇÃO E SOCIEDADE. São Paulo, Ed. Cortez, n. 3, 1979.

EDUCAÇÃO E SOCIEDADE. Campinas, Ed. Cortez, n. 5, 1980.

EDUCAÇÃO E SOCIEDADE. São Paulo, Ed. Cortez, n. 6, 1980.

FALEIROS, Marlene de Oliveira Lobo. Repensando o Currículo de Pedagogia da Faculdade de Educação da UFG. Goiânia, 1993. (mimeo).

FORQUIM, Jean Claude. Sociologia da Educação: dez anos de pesquisa. Trad. Guilherme João de Freitas Teixeira. Petrópolis, Ed. Vozes, 1995.

GARRIDO, Joan del Alcàzar. As fontes orais na pesquisa histórica: uma introdução ao debate. Revista Brasileira de História. São Paulo, Ed. Marco Zero, v. 13, p. 33-54, 1993.

GERMANO, José Wellington. Estado Militar e Educação no Brasil. São Paulo: Cortez, 1994.

GOIÁS. Comissão Coordenadora do Estado de Goiás para a "Reformulação dos Cursos de Preparação de Recursos Humanos para a Educação. Boletim n. 1, 1983a.

.Comissão estadual para Reformulação dos Cursos de Preparação de Recursos Humanos para a Educação. Documento conclusivo do Encontro Estadual de Goiás. Goiânia, 1983b. (Mimeogr.).

.Comissão de Reformulação do Curso de Pedagogia e da Formação Pedagógica das Demais Licenciaturas. Quanto à formação do técnico. Goiânia, 1983c. (Mimeogr.).

GOODSON, Ivor F. Currículo: teoria e história. Petrópolis, Vozes, 1995.

JANOTTI, Maria De Loudes Monaca e ROSA, Zita de Paula. História Oral: uma utopia ?. Revista Brasileira de História. São Paulo, Ed. Marco Zero. v. 13, n. 25/26, p. 7-16, set. 1992/ ago. 1993.

LOUREIRO, Marcos Correia da Silva, FALEIRO, Marlene de Oliveira Lobo e ALMEIDA, Maria Zeneide Carneiro Magalhães de. Subsídio para uma avaliação de currículo: o caso do curso de Pedagogia da Universidade Federal de Goiás. Aval. Pol. Públ., Rio de Janeiro, v. 4, n. 11, p. $183-$ 196, abr./jun., 1996.

LÜDKE, Menga e ANDRË, Marli E. D. A pesquisa em educação: abordagens qualitativas. São Paulo, EPU, 1986. 
MONTENEGRO, Antônio Torres. História Oral: caminhos e descaminhos. Revista Brasileira de História. São Paulo, Ed. Marco Zero. v. 13, n. 25/26, p. 55-66, set. 1992/agot. 1993.

MOREIRA, Antônio Flávio Barbosa. História do Currículo: examinando contribuições e alternativas. Encontro Nacional de Didática e Prática de Ensino, 7, 1994, Goiânia. Anais: conferências, mesas redondas e simpósios. Goiânia, v. 2, 1994. p. 273-284.

. Currículos e Programas no Brasil. Campinas, Papirus, 1997 (Coleção Formação e Trabalho Pedagógico).

MOREIRA, Antônio Flávio Barbosa e SILVA, Tomaz Tadeu da (orgs). Sociologia e teoria do currículo: uma introdução. p. 7-37. Currículo, Cultura e Sociedade. São Paulo: Cortez, 1994.

PEREIRA DE QUEIROZ, Maria Isaura Pereira de. Relatos orais: do "indizível" ao "dizível" In VON SIMON, Olga de Moraes (org.). Experimentos com histórias de vida: Itália-Brasil. São Paulo: Vértice; Ed. Revista dos Tribunais, 1988, p. 14-43.

REVISTA INTER-AÇÃO, Revista da Faculdade de Educação da UFG. Goiânia, v. 5, n. 8, p. $103-$ $136,1981$.

ROMANELLI, Otaísa de Oliveira. História da Educação no Brasil (1930/1973). 20 ed., Petrópolis, Vozes, 1998.

SANTOS, Lucíola Licínio C. P. Problemas e alternativas no campo da formação de professores. Revista Brasileira de Estudos Pedagógicos. Brasília, v. 72, n. 172, p. 318-334, 1991.

. Formação do professor e pedagogia crítica In: ARANTES, Ivani Catarina (org.) $A$ pesquisa em educação e as transformações do conhecimento. Campinas: Papirus, 1997 (Coleção Práxis).

SANTOS, Lucíola Licínio Castro Paixão e OLIVEIRA, Maria Rita Neto Sales. Currículo e Didática In: OLIVEIRA, Maria Rita Neto Sales (org.) Confluências e divergências entre didática e currículo. Campinas: Papirus, 1998 (Série Prática Pedagógica)

SILVA, Tomaz Tadeu. Identidades terminais. Petrópolis, Editora Vozes Ltda, 1996.

ULHOA, Joel Pimentel de. Para revisão curricular dos cursos de Pedagogia e Licenciatura. Goiânia, 22 de setembro, 1979. (mimeo). 